\title{
Grafting of Polymers onto Carbon Microcoil Surface by Ligand-Exchange Reaction of Ferrocene Moieties of Polymer with Polycondensed Aromatic Rings of the Surface
}

\author{
Haruo Morohashi, ${ }^{1}$ Yuji Nishida, ${ }^{1}$ Yukimune TAKAhashi, ${ }^{1}$ Kazuhiro FujIKI, ${ }^{2}$ \\ Takeshi Yamauchi, ${ }^{1,3}$ Norio TsuboKawa, ${ }^{3,4, \dagger}$ and Seiji Motouma ${ }^{5}$ \\ ${ }^{1}$ Graduate School of Science and Technology, Niigata University, 8050, Ikarashi 2-nocho, Niigata 950-2181, Japan \\ ${ }^{2}$ Division of Life and Health Sciences, Joetsu University of Education, 1, Yamayashiki, Joetsu 943-8521, Japan \\ ${ }^{3}$ Center for Transdisciplinary Research, Niigata University, 8050, Ikarashi 2-nocho, Niigata 950-2181, Japan \\ ${ }^{4}$ Department of Material Science and Technology, Faculty of Engineering, Niigata University, \\ 8050, Ikarashi 2-nocho, Niigata 950-2181, Japan \\ ${ }^{5}$ Faculty of Engineering, Gifu University, 1-1, Yanagido, Gifu 501-1193, Japan
}

(Received October 2, 2006; Accepted November 16, 2006; Published December 27, 2006)

\begin{abstract}
To improve the dispersibility of carbon microcoil (CMC) in solvents and polymer matrices, the grafting of copolymer containing vinyl ferrocene (VFE) onto surface by ligand-exchange reaction with ferrocene moieties of the copolymer and polycondensed aromatic rings of CMC was investigated. The copolymer containing VFE was prepared by the radical copolymerization of VFE with vinyl monomers, such as methyl methacrylate (MMA) and styrene (St), using 2,2'-azobisisobutyronitrole as an initiator. It was found that by heating of CMC with poly(VFE-co-MMA) and poly(VTE-co-St) in the presence of $\mathrm{AlCl}_{3}$ and $\mathrm{Al}$ powder as catalyst, these copolymers were grafted onto the surface: the percentage of grafting reached to $64.2 \%$. On the contrary, in the absence of $\mathrm{AlCl}_{3}$, no grafting of the copolymer was observed. The grafting of polymers onto the CMC surface was confirmed by attenuated total reflection Fourier transform infrared (ATR-FTIR), thermal decomposition gas chromatography-mass spectroscopy (GC-MS) and fieldemission scanning electron microscope (FE-SEM). Therefore, it is considered that the copolymer was grafted onto CMC surface by ligand-exchange reaction with ferrocene moieties of the copolymer and polycondensed aromatic rings of CMC. The polymer-grafted CMC gave a stable dispersion in solvents for grafted polymer.

[doi:10.1295/polymj.PJ2006124]

KEY WORDS Carbon Microcoil / Polymer Grafting / Ligand-Exchange Reaction / Polycondensed Aromatic Ring / Vinyl Ferrocene / Dispersibility /
\end{abstract}

Carbon microcoil (CMC) is a new class of carbon fiber with helical/spiral forms with a coil diameter of $\mu \mathrm{m}$ orders, and a possible candidate for electromagnetic absorber, ${ }^{1}$ hydrogen absorber, ${ }^{2}$ tactile sensor, ${ }^{3}$ etc.

However, it is hardly achieved to disperse CMC in various solvents and polymer matrices uniformly due to the unique morphology and the very few surface functional groups. It is expected that the surface treatments of conventional carbon fiber, such as oxidative treatments, ${ }^{4-8}$ electrochemical treatments, ${ }^{9}$ coating, and grafting, ${ }^{10,11}$ can be used for the modification of the surface of CMC.

We have reported the surface grafting of polymers onto carbon materials, such as carbon black, graphite, carbon nanotubes, and carbon fibers. ${ }^{12,13}$ For example, we have reported that the anionic ring-opening alternating copolymerization of epoxides with cyclic acid anhydrides are successfully initiated by COOK groups previously introduced onto carbon fiber and carbon nanofiber surfaces and the corresponding polymers are grafted onto the surfaces. ${ }^{14,15}$ In addition, it has been reported that the cationic polymerization of $N$ vinylcarbazole and $\mathrm{N}$-vinyl-2-pyrrolidone are initiated by surface carboxyl groups on carbon fiber to give the corresponding polymer-grafted carbon fiber. ${ }^{16}$ Furthermore, we demonstrated that the radical graft polymerization of vinyl monomers is initiated from surface radicals formed on carbon fiber. ${ }^{17}$ We have also reported the radical graft polymerization of vinyl monomers initiated by the system consisting of $\mathrm{Mo}(\mathrm{CO})_{6}$ and trichloroacetylchloride group on carbon fiber. ${ }^{18}$

On the other hand, we have reported the grafting of polymers by ligand-exchange reaction of ferrocene moieties of polymers with polycondensed aromatic rings of carbon black, carbon fiber, and carbon nanofibers. ${ }^{19-21}$ We have pointed out that the surface grafting by the ligand-exchange reaction between ferrocene moieties of the copolymer and the polycondensed aromatic rings of carbon materials is very effective for the grafting of polymers onto carbon mate-

${ }^{\dagger}$ To whom correspondence should be addressed (Tel/Fax: +81-25-262-6779, E-mail: ntsuboka@eng.niigata-u.ac.jp). 

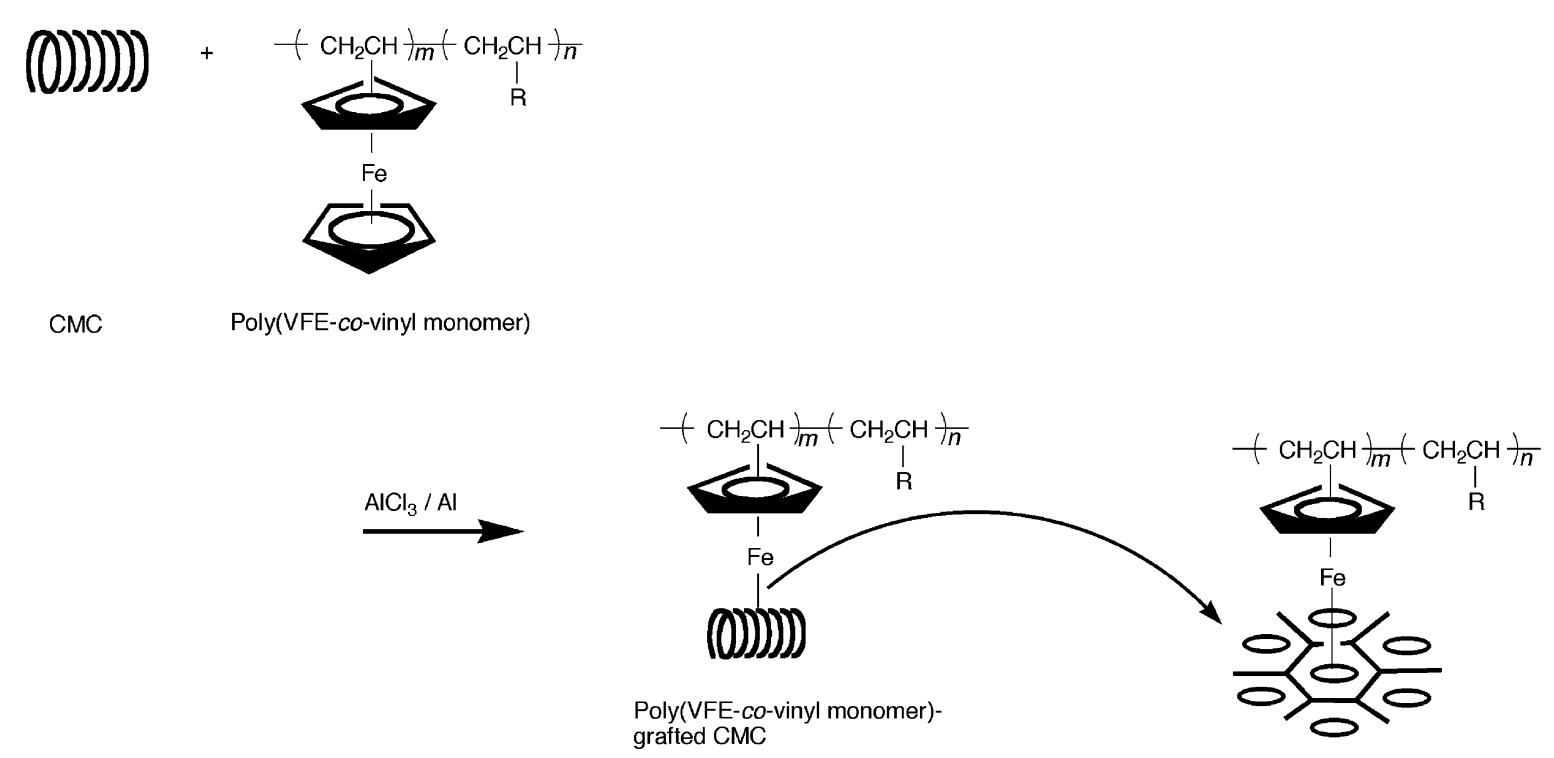

Scheme 1. Grafting of poly(VFE-co-vinyl monomer) onto surface of CMC by ligand-exchange reaction.

rials having few functional groups.

In this paper, we investigated the grafting of copolymers containing vinyl ferrocene onto CMC surface by ligand-exchange reaction of ferrocene moieties of polymer with polycondensed aromatic rings of CMC surface as shown in Scheme 1. The dispersibility of polymer-grafted CMC will be also discussed.

\section{EXPERIMENTAL}

\section{Materials and Reagents}

Carbon microcoil (CMC) was supplied from CMC Technology Development Co., Ltd. Japan and dried in vacuum at $120^{\circ} \mathrm{C}$ before use. The coil diameter, fiber diameter, and fiber length of CMC are $1-3 \mu \mathrm{m}$, $0.1 \mu \mathrm{m}$, and $90-150 \mu \mathrm{m}$, respectively. The bulk density of CMC is $1.72 \mathrm{~g} / \mathrm{cm}^{3}$.

Methyl methacrylate (MMA), styrene (St), vinyl ferrocene (VFE), and 2,2'-azobisisobutyronitrile (AIBN) were obtained from Aldrich Chem. Co. and purified by the ordinary methods. Toluene and 1,4dioxane were used after ordinary purification. $\mathrm{AlCl}_{3}$, $\mathrm{Al}$ powder (particle size: $53-150 \mu \mathrm{m}$ ) obtained from Aldrich Chem. Co. were used without further purification.

\section{Preparation of Poly(VFE-co-Vinyl Monomer)}

Poly(VFE-co-MMA) and poly(VFE-co-St) were prepared by radical copolymerization of VFE with MMA and St, respectively. The detailed procedures were described in the previous paper. ${ }^{19-21}$

The composition of the copolymer was determined by the maximum absorbance at $440 \mathrm{~nm}$, assignable to ferrocene moiety in the copolymer. Ferrocene was used as a standard substance for the composition determination. The number-average molecular weight
$\left(M_{\mathrm{n}}\right)$ and molecular weight distribution of the copolymer were estimated by size exclusion chromatography (SEC), using polystyrene standards. For SEC, a Tosoh CCPD instrument equipped with TSK-GEL G3000H $\mathrm{HL}_{\mathrm{X}}$ column was used.

\section{Grafting of Poly(VFE-co-Vinyl Monomer) onto CMC Surface}

Into a flask, $50.0 \mathrm{mg}$ of $\mathrm{CMC}, 50.0 \mathrm{mg}$ of poly(VFE-co-vinyl monomer), $\mathrm{AlCl}_{3}, \mathrm{Al}$ powder, and $10.0 \mathrm{~mL}$ of 1,4-dioxane were charged and the mixture was stirred for a definite time with a magnetic stirrer under nitrogen. The stirring rate was adjusted at $150 \mathrm{rpm}$ in order to prevent the breaking of coil structure of CMC. After the reaction, the quenching of $\mathrm{AlCl}_{3}$ was achieved by the addition of methanol into the reaction mixture.

To separate the copolymer-grafted CMC from the reaction mixture containing ungrafted copolymer and $\mathrm{Al}$ powder, the product was dispersed in 1,4-dioxane under the irradiation of ultrasonic wave. Then, the dispersion of copolymer-grafted CMC was allowed to stand at room temperature and $\mathrm{Al}$ powder precipitated was removed by decantation. The dispersion of polymer-grafted CMC was centrifuged at $1.5 \times 10^{4} \mathrm{rpm}$ and the precipitated polymer-grafted $\mathrm{CMC}$ was dispersed again in 1,4-dioxane. The procedures were repeated several times to remove most of ungrafted copolymer. To remove adsorbed $\mathrm{AlCl}_{3}$ on the polymer-grafted CMC surface, the copolymergrafted CMC was washed for $30 \mathrm{~min}$ in $1.0 \mathrm{~mol} / \mathrm{L}$ $\mathrm{HCl}$ under stirring with a magnetic stirrer.

\section{Percentage of Grafting}

The percentage of polymer grafting was calculated by the following equation. 
Table I. Grafting of poly(VFE-co-vinyl monomer) onto CMC by ligand-exchange reaction under various conditions

\begin{tabular}{clcccr}
\hline Run No. & \multicolumn{1}{c}{ Polymer } & $\begin{array}{c}\text { VFE in copolymer } \\
(\mathrm{mol} \%)\end{array}$ & $\begin{array}{c}\mathrm{AlCl}_{3} \\
(\mathrm{mmol})\end{array}$ & $\begin{array}{c}\mathrm{Al} \\
(\mathrm{mmol})\end{array}$ & $\begin{array}{c}\text { Grafting } \\
(\%)\end{array}$ \\
\hline 1 & Poly(VFE-co-MMA) & 14 & - & - & 2.4 \\
2 & Poly(VFE-co-MMA) & 14 & - & 0.875 & 1.9 \\
3 & Poly(VFE-co-MMA) & 14 & 3.5 & - & 31.0 \\
4 & Poly(VFE-co-MMA) & 14 & 3.5 & 0.875 & 35.0 \\
5 & Poly(VFE-co-St) & 7 & 3.5 & 0.875 & 5.0 \\
\hline
\end{tabular}

CMC, $50.0 \mathrm{mg}$; poly(VFE-co-vinyl monomer), $50.0 \mathrm{mg} ; 1,4$-dioxane, $10.0 \mathrm{~mL} ; 80^{\circ} \mathrm{C} ; 24 \mathrm{~h}$.

$$
\text { Grafting }(\%)=(\mathrm{A} / \mathrm{B}) \times 100 \text {, }
$$

where A is polymer grafted $(\mathrm{g})$ and $\mathrm{B}$ is CMC used (g). The amount of polymer grafted onto the CMC surface was determined by weight loss when the polymer-grafted $\mathrm{CMC}$ was heated from room temperature to $500{ }^{\circ} \mathrm{C}$ under nitrogen at $10^{\circ} \mathrm{C} / \mathrm{min}$ by using a thermal analyzer (Shimadzu Thermogravimetric Analyzer TGA-50). Considering iron which formed during the thermal decomposition of the copolymer, the weight of grafted polymer (A) was calculated.

\section{Dispersibility of Poly(VFE-co-MMA)-Grafted CMC}

Poly(VFE-co-MMA)-grafted CMC (10.0 mg) was dispersed in $5.0 \mathrm{~mL}$ of THF, toluene, 1,4-dioxane and water and allowed to stand at room temperature. The time until polymer-grafted CMC completely precipitated was compared with that of ungrafted one.

The dispersion state of poly(VFE-co-MMA)-grafted CMC in 1,4-dioxane was observed by an optical microscope (ECLIPSE ME600P: Nikon). The sample was prepared as follows: dispersion of poly(VFEco-MMA)-grafted CMC (50.0 mg) in $5.0 \mathrm{~mL}$ of $1,4-$ dioxane was dropped onto a slide glass and the drop was covered with a cover glass.

\section{Characterization}

Attenuated total reflection Fourier transform infrared (ATR-FTIR) spectra were recorded by a FTIR spectrometer (Spectrum One: Perkin-Elmer) equipped with an ATR measurement attachment (MIRacle: PIKE).

Grafted polymer on CMC surface was identified by thermal decomposition gas of grafted polymer by using gas chromatography-mass spectroscopy (GC-MS). The thermal decomposition GC-MS was recorded by a GCMS-QP2010 gas chromatograph mass spectrometer (Shimadzu Manufacturing Co., Ltd) equipped with a double shot pyrolyzer (Frontier Laboratories Ltd). The GC was equipped with Ultra ALLOY-5 column $(30 \mathrm{~m}$ by $0.25 \mathrm{~mm}$ i.d., $0.25 \mu \mathrm{m}$ film thickness). Helium was used as the carrier gas. The column was programmed from 70 to $320^{\circ} \mathrm{C}$ at a heating rate of $20^{\circ} \mathrm{C} / \mathrm{min}$ and then held at $320^{\circ} \mathrm{C}$ for $5 \mathrm{~min}$.
The morphology of CMC surface was observed by a field-emission scanning electron microscope (FESEM) (JSM-6330F: JEOL) at an acceleration voltage of $5.0 \mathrm{kV}$.

\section{RESULTS AND DISCUSSION}

\section{Preparation Poly(VFE-co-Vinyl Monomer) and Char- acterization}

Poly(VFE-co-MMA) and poly(VFE-co-St) were prepared by the copolymerization of VFE with MMA and St, respectively, using AIBN as an initiator. ${ }^{22,23}$ The number-average molecular weight of poly(VFE-coMMA) and poly(VFE-co-St) was estimated to be $6.5 \times 10^{4}$ and $4.2 \times 10^{4}$, respectively. The content of ferrocene moieties of poly(VFE-co-MMA) and poly(VFE-co-St) were determined to be $14 \mathrm{~mol} \%$ and $7 \mathrm{~mol} \%$, respectively.

The infrared spectrum of poly(VFE-co-MMA) shows a new absorption at $820 \mathrm{~cm}^{-1}$, which is characteristic of ferrocene moiety. Furthermore, it was found that poly(MMA) was pyrolyzed completely at about $400^{\circ} \mathrm{C}$. On the contrary, these copolymers containing VFE moieties were hardly pyrolyzed completely, indicating the presence of ferrocene moieties in the copolymer.

\section{Grafting of Poly(VFE-co-Vinyl Monomer) onto CMC}

The grafting of poly(VFE-co-MMA) onto CMC surface by ligand-exchange reaction between ferrocene moieties of the copolymer and polycondensed aromatic rings of CMC was investigated. Table I shows the results of grafting reaction of poly(VFE-co-MMA) with CMC surface under several conditions. As shown in Table I, even if CMC was heated with poly(VFEco-MMA) in 1,4-dioxane in the absence of $\mathrm{AlCl}_{3}$ and $\mathrm{Al}$ powder, no grafting of the copolymer onto the surface was observed (Run 1). In addition, the grafting of the copolymer onto CMC surface was hardly observed in the presence of $\mathrm{Al}$ powder alone (Run 2).

On the contrary, the grafting reaction considerably proceeded in the presence of $\mathrm{AlCl}_{3}$ (Run 3). In the coexistence of $\mathrm{AlCl}_{3}$ and $\mathrm{Al}$ powder, poly(VFE-coMMA) was successfully grafted onto wall surface of 


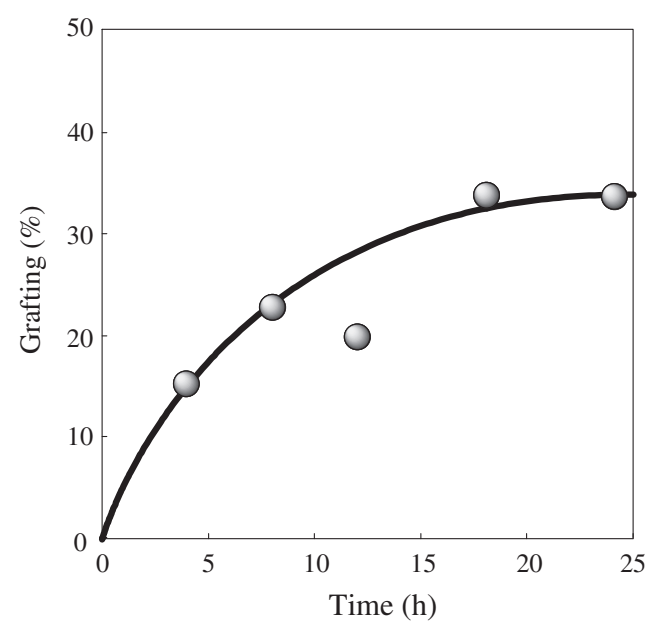

Figure 1. Relationship between reaction time and percentage of grafting in the ligand-exchange reaction of poly(VFE-coMMA) with CMC surface at $80^{\circ} \mathrm{C}$. CMC, $50.0 \mathrm{mg}$; poly(VFE-coMMA), $50.0 \mathrm{mg}$; 1,4-dioxane, $10.0 \mathrm{~mL}$; $\mathrm{AlCl}_{3}, 3.5 \mathrm{mmol}$; $\mathrm{Al}$ powder, $0.875 \mathrm{mmol}$.

CMC and the percentage of grafting reached to $35.0 \%$ after $24 \mathrm{~h}$ at $80^{\circ} \mathrm{C}$ (Run 4).

In addition, poly(VFE-co-St) was also successfully grafted onto CMC surface by the ligand-exchange reaction as shown in Table I (Run 5). The grafting of poly(VFE-co-St) was smaller than that of poly(VFEco-MMA). This may be due to the small content of VFE moieties of poly(VFE-co-St). The same tendency was observed in the grafting of poly(VFE-co-St) onto VGCF surface by ligand-exchange reaction. ${ }^{21}$

After the grafting of the copolymers, iron in ferrocene moiety exists in reduced form, ${ }^{24}$ because it is known that $\mathrm{Al}$ powder prevents ferrocene from being oxidized to ferricinium cation. ${ }^{25}$

Figure 1 shows time-grafting curve during the ligand-exchange reaction of CMC with poly(VFE-coMMA) at $80^{\circ} \mathrm{C}$. The percentage of grafting increased with reaction time, but no longer increased after $24 \mathrm{~h}$. This may be due to the fact that CMC surface was blocked by the grafted polymer chains.

\section{Effect of the Catalyst on Grafting}

We have reported that ligand-exchange reaction of copolymer containing VFE with carbon materials are affected by the amount of catalyst. ${ }^{19-21}$ Therefore, the effect of the amount of catalyst $\left(\mathrm{AlCl}_{3}\right.$ and $\mathrm{Al}$ powder) on the grafting reaction was investigated by fixing the amount of poly(VFE-co-MMA) charged and the molar ratio between $\mathrm{AlCl}_{3}$ and $\mathrm{Al}$ powder at $4: 1$.

As shown in Table II, the percentage of grafting increased with an increasing amount of $\mathrm{AlCl}_{3}$ and Al powder, but no longer increased above 7.0 and $1.75 \mathrm{mmol}$, respectively. This may be due to the
Table II. Ligand-exchange reaction of poly(VFE-co-MMA) with $\mathrm{CMC}$ under various conditions

\begin{tabular}{cccc}
\hline $\mathrm{AlCl}_{3}(\mathrm{mmol})$ & $\mathrm{Al}(\mathrm{mmol})$ & Solvent & Grafting $(\%)$ \\
\hline- & - & 1,4-dioxane & 2.4 \\
1.0 & 0.250 & 1,4-dioxane & 24.7 \\
3.5 & 0.875 & 1,4 -dioxane & 35.0 \\
7.0 & 1.750 & 1,4 -dioxane & 64.2 \\
14.0 & 3.500 & 1,4 -dioxane & 59.9 \\
3.5 & 0.875 & toluene & 20.6 \\
\hline
\end{tabular}

CMC, $0.05 \mathrm{~g} ;$ poly(VFE-co-MMA), $0.05 \mathrm{~g} ;$ 1,4-dioxane, $10.0 \mathrm{~mL} ; 80^{\circ} \mathrm{C} ; 24 \mathrm{~h}$.

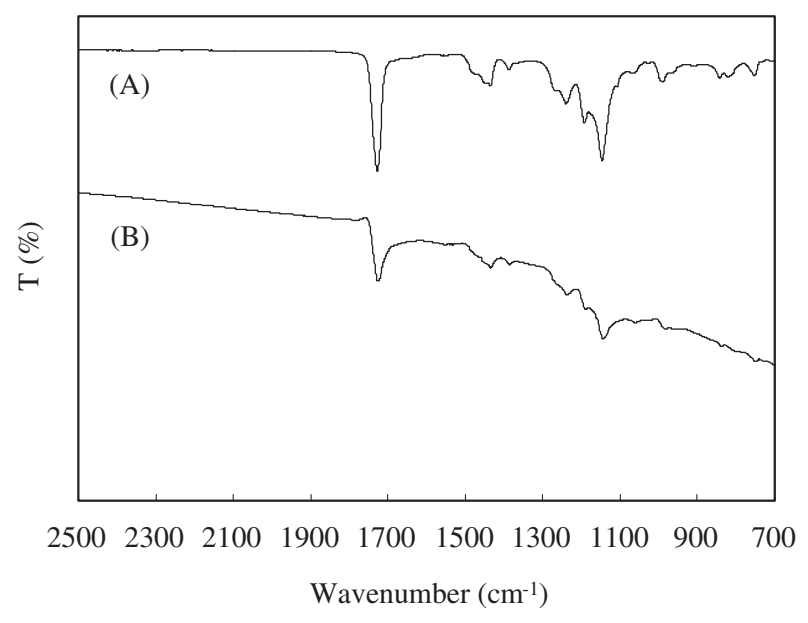

Figure 2. ATR-FTIR spectra of (A) poly(VFE-co-MMA) and (B) poly(VFE-co-MMA)-grafted CMC.

CMC surface was blocked by grafted polymer chains. The same tendency was observed during the grafting reaction of surface functional groups on carbon black with functional polymers. ${ }^{26}$ For this reason, the maximum grafting was achieved by use of $50.0 \mathrm{mg}$ of $\mathrm{CMC}, 7.0 \mathrm{mmol}$ of $\mathrm{AlCl}_{3}$, and $1.75 \mathrm{mmol}$ of $\mathrm{Al}$ powder.

Table II also shows solvent effect on the grafting by ligand-exchange reaction. The grafting onto CMC by the ligand-exchange reaction in 1,4-dioxane was larger than that in toluene. The result indicates that the ligand-exchange reaction was accelerated in polar solvent.

\section{Characterization of Poly(VFE-co-MMA)-Grafted CMC}

Figure 2 shows ATR-FTIR spectra of (A) poly(VFE-co-MMA) and (B) poly(VFE-co-MMA)-grafted CMC. As shown in Figure 2, ATR-FTIR spectra of poly(VFE-co-MMA)-grafted CMC show absorptions characteristic of poly(VFE-co-MMA). The result also shows the grafting of poly(VFE-co-MMA) onto CMC surface.

Figure 3 shows gas chromatogram (GC) of thermally decomposed gas of (A) poly(VFE-co-MMA) and 
(B) poly(VFE-co-MMA)-grafted CMC. GC of decomposed gas of poly(VFE-co-MMA)-grafted CMC was in agreement with that of poly(VFE-co-MMA). Mass spectra of decomposed gas of poly(VFE-co-MMA)grafted $\mathrm{CMC}$ at retention time $1.31 \mathrm{~min}$ was also in agreement with that of poly(VFE-co-MMA). The results also show poly(VFE-co-MMA) was grafted onto CMC surface.

\section{FE-SEM Aspect of Poly(VFE-co-MMA)-Grafted CMC}

Figure 4 shows FE-SEM aspects of (A) ungrafted and (B) poly(VFE-co-MMA)-grafted CMC. The ungrafted $\mathrm{CMC}$ shows smooth surface, but the grafted polymer can be observed on poly(VFE-co-MMA)grafted $\mathrm{CMC}$ surface. The results also suggest that poly(VFE-co-MMA) was grafted onto CMC surface.
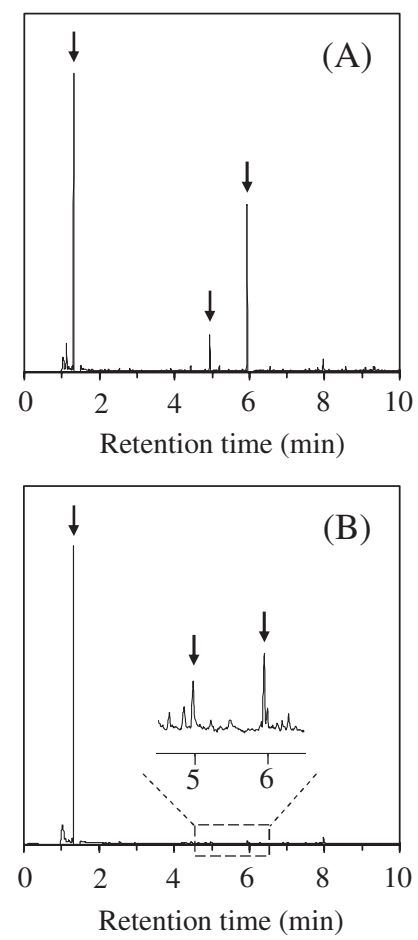

Figure 3. Thermal decomposition GC of (A) poly(VFE-coMMA) and (B) poly(VFE-co-MMA)-grafted CMC.

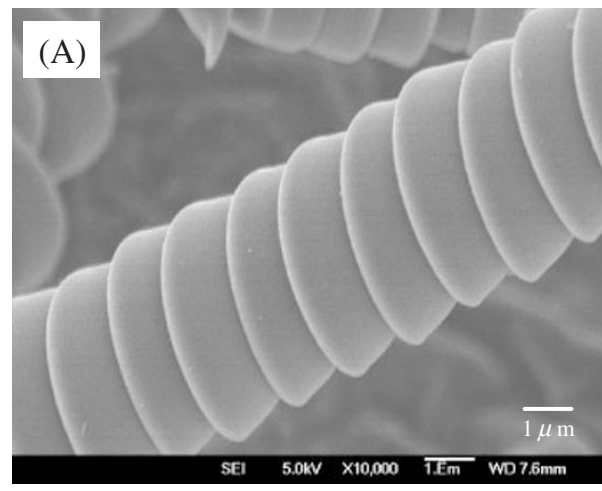

On the basis of the aforementioned results, it is suggested that the grafting of copolymers containing VFE onto CMC surface should proceed by the ligandexchange reaction between ferrocene moieties of the copolymer and polycondensed aromatic rings of CMC as shown in Scheme 1.

\section{Dispersibility of Polymer-Grafted CMC}

The dispersibility of poly(VFE-co-MMA)-grafted CMC in THF, toluene, 1,4-dioxane and water was examined. The results are shown in Figure 5. Ungrafted CMC completely precipitated in THF, toluene and 1,4-dioxane within $5 \mathrm{~min}$. On the contrary, poly-
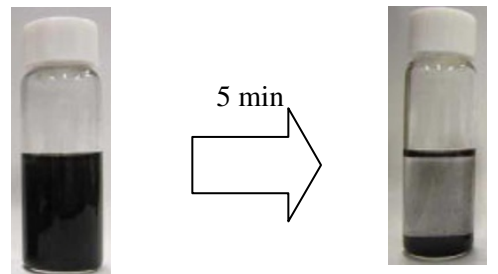

Ungrafted CMC in THF
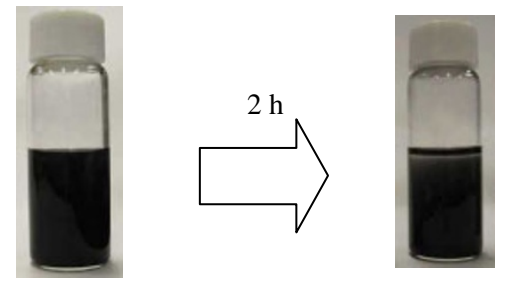

Poly(VFE-co-MMA)-grafted CMC in THF
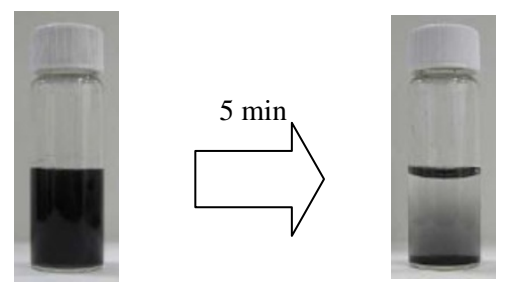

Poly(VFE-co-MMA)-grafted CMC in water

Figure 5. Dispersibility of ungrafted CMC in THF and poly(VFE-co-MMA)-grafted CMC in THF and water at room temperature.

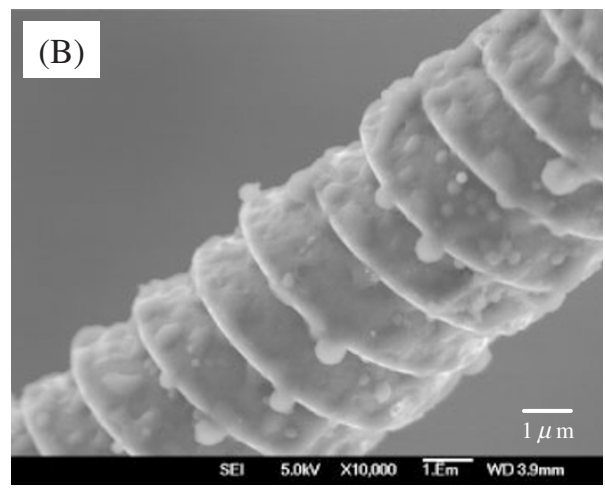

Figure 4. FE-SEM aspects of (A) ungrafted and (B) poly(VFE-co-MMA)-grafted CMC (grafting: 35.0\%). 

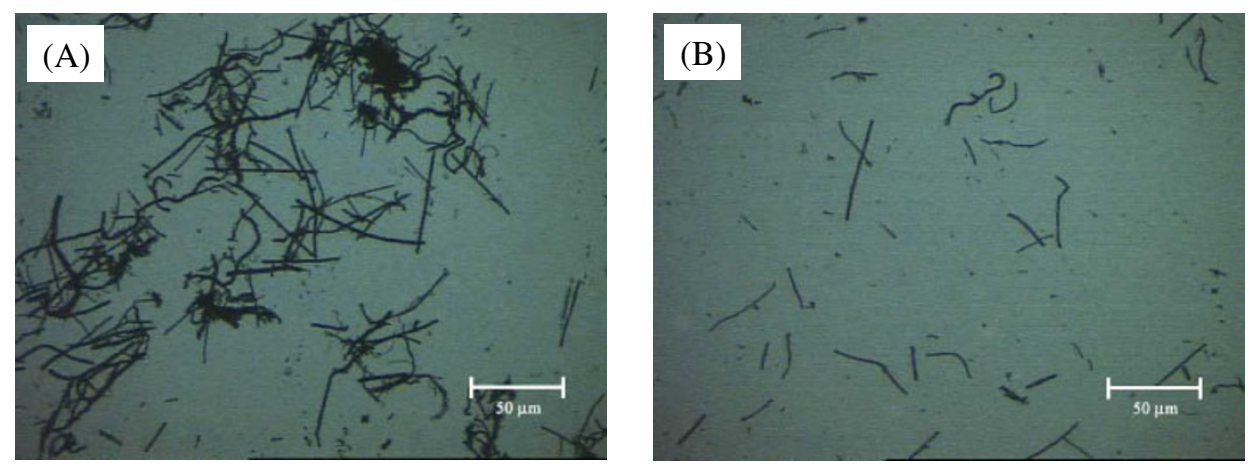

Figure 6. Optical micrographs of (A) ungrafted and (B) poly(VFE-co-MMA)-grafted CMC in 1,4-dioxane.

(VFE-co-MMA)-grafted CMC gave a stable dispersion in THF, toluene and 1,4-dioxane, which is good solvent for grafted chain. However, poly(VFE-coMMA)-grafted CMC completely precipitated in water, which is poor solvent for grafted polymer, within 5 min.

Figure 6 shows optical micrographs of (A) ungrafted and (B) poly(VFE-co-MMA)-grafted CMC in 1,4dioxane. The dispersion of ungrafted CMC in 1,4dioxane is not uniform and large agglomerates of ungrafted $\mathrm{CMC}$ can be found. On the contrary, poly(VFE-co-MMA)-grafted CMC in 1,4-dioxane gave considerably uniform dispersion.

The results indicate that by the grafting of poly(VFE-co-MMA) onto CMC surface, the intertwined structure of CMC was effectively destroyed and grafted polymer chains on the surface interfere with aggregation of the CMC in good solvents for grafted polymer.

\section{CONCLUSIONS}

1. The grafting of poly(VFE-co-MMA) and poly(VFE-co-St) onto CMC surface was successfully achieved by the ligand-exchange reaction between ferrocene moieties of the copolymer and the polycondensed aromatic rings of CMC.

2. The surface grafting by use of ligand-exchange reaction of ferrocene moieties of the copolymer with the polycondensed aromatic rings of CMC is very effective to obtain CMC with higher percentage of grafting.

3. Polymer-grafted CMC gave a stable dispersion in good solvents of grafted polymer.

\section{REFERENCES}

1. S. Motojima, Y. Hishikawa, and H. Iwanaga, Recent Develop. Mater. Sci., 3, 633 (2002).

2. Y. Furuya, T. Hashishin, H. Iwanaga, S. Motojima, and Y. Hishikawa, Carbon, 42, 331 (2004).

3. X. Chen, S. Yang, M. Hasegawa, K. Kawabe, and S.
Motojima, Appl. Phys. Lett., 87, 54101 (2005).

4. S. Gardner, C. Singamsetty, G. Booth, G. He, and C. Pittman, Carbon, 33, 587 (1995).

5. H. Bubert, X. Ai, S. Haiber, M. Heintze, V. Brüser, E. Pasch, W. Brandl, and G. Marginean, Spectrochim. Acta, Part B, 57, 1601 (2002).

6. E. Desimoni, A. M. Salvi, F. Langerame, and J. F. Watts, J. Electron Spectrosc. Relat. Phenom., 85, 179 (1997).

7. R. Pogue, J. Ye, A. Klosterman, A. Glass, and R. Chartoff, Composites Part A, 29, 1273 (1998).

8. P. Serp, J. Figueiredo, P. Bertrand, and J. Issi, Carbon, 36, 1791 (1998).

9. S. Waseem, S. Gardner, G. Hea, W. Jiang, and C. Pittman, J. Mater. Sci., 33, 3151 (1998).

10. N. Tsubokawa and K. Fujiki, in "Polymeric Materials Encyclopedia,” J. C. Salamone, Ed. CRC Press New York, 1996, vol. 5, p 3251.

11. W. Shen, I. Parker, and Y. Sheng, J. Adhes. Sci. Technol., 12, 161 (1998).

12. N. Tsubokawa, Bull. Chem. Soc. Jpn., 75, 2115 (1992).

13. N. Tsubokawa, Polym. J., 37, 637 (2005).

14. N. Tsubokawa, H. Hamada, and Y. Sone, Polym.-Plast. Technol. Eng., 28, 201 (1989).

15. G. Wei, K. Fujiki, H. Saitoh, K. Shirai, and N. Tsubokawa, Polym. J., 36, 316 (2004).

16. N. Tsubokawa, H. Maruyama, and Y. Sone, Polym. Bull., 15, 209 (1986).

17. R. Yosomiya and T. Fujisawa, Polym. Bull., 13, 7 (1985).

18. G. Wei, K. Fujiki, H. Saitoh, K. Shirai, and N. Tsubokawa, Carbon, 42, 1923 (2004).

19. N. Tsubokawa, N. Abe, Y. Seida, and K. Fujiki, Chem. Lett., 29, 900 (2000).

20. N. Tsubokawa, N. Abe, G. Wei, J. Chen, and S. Saitoh, J. Polym. Sci., Part A: Polym. Chem., 40, 1868 (2002).

21. G. Wei, S. Saitoh, H. Saitoh, K. Fujiki, T. Yamauchi, and N. Tsubokawa, Polymer, 45, 8723 (2004).

22. M. G. Baldwin and K. Johnson, J. Polym. Sci., Part A-1, 5, 2091 (1967).

23. J. C. Lai, T. Rounsfell, and C. U. Pittman, J. Polym. Sci., Part A-1, 9, 651 (1971).

24. M. Miyake, K. Yasuda, T. Kashihara, and T. Teranishi, Chem. Lett., 28, 1037 (1999).

25. A. N. Nesmeyanov, N. A. Vol'kenau, and I. N. Bolesova, Tetrahedron Lett., 1725 (1963).

26. N. Tsubokawa, Nippon Kagaku Kaishi, 1012 (1993). 